\title{
Radiotherapy in Pakistan
}

\author{
Ahmad Mushtaq \\ Isotope Production Division, Pakistan Institute of Nuclear Science and Technology, Islamabad, Pakistan \\ Email: amushtaq1@hotmail.com
}

Received 23 April 2014; revised 25 May 2014; accepted 3 June 2014

Copyright (C) 2014 by author and OALib.

This work is licensed under the Creative Commons Attribution International License (CC BY).

http://creativecommons.org/licenses/by/4.0/

(c) (1) Open Access

\begin{abstract}
In Pakistan we do not have a National Cancer Registry. Some institutions have started to develop their own Cancer Registry. According to the World Health Organisation annually 120,000 people in Pakistan are diagnosed with cancer. All three types of radiotherapy procedures, teletherapy, brachytherapy and unsealed sources are being employed for treatment of cancer. Accelerators and Cobalt-60 teletherapy units are imported. Radioisotopes used as radiotherapeutics are produced locally. IAEA is constantly supporting the activities of radiotherapy in Pakistan. Infrastructure of radiotherapy needs extensive improvement in Pakistan. Clinical applications of radiotherapeutics can only be increased by collaboration of nuclear medical centers and producer of radionuclides-Pakistan Institute of Nuclear Science and Technology (PINSTECH), Islamabad, Pakistan.
\end{abstract}

\section{Keywords}

Radioisotope, Radiotherapy, Teletherapy, Brachytherapy, Cancer, Pakistan

Subject Areas: Oncology, Radiology \& Medical Imaging

\section{Introduction}

Radiotherapy is a major cancer therapy along with chemotherapy and surgery. Radiotherapy utilizes ionizing radiation such as X-ray, gamma-ray and electron beams to treat cancers. Radiotherapy is provided to cancer patients alone or in combination with surgery or chemotherapy as a curative therapy, adjuvant therapy, and palliative care. The role of radiotherapy is readily demonstrated by the fact that, while the use of radiotherapy dose vary depending on the types of cancer being treated, overall, more than $50 \%$ of all the cancer patients require radiotherapy sometime during the course of the treatment of their illnesses.

There are three main ways of delivering radiotherapy:

1) External radiotherapy or teletherapy is the delivery of beams produced by a source outside of the body. 
2) Internal radiotherapy or brachytherapy is the delivery of the radioactive source via an implanted unit.

3) Unsealed source is the process of attaching a radioactive isotope to a chemical/metabolite and injecting into the body. This has been used in neuroblastoma patients.

Radiotherapy, the treatment of cancer by radiation, can, in many cases, save lives. Even in cases where the disease is too advanced to be cured, radiotherapy can provide palliation that allows patients to live out their lives as comfortable as possible. Radiotherapy remains an unattainable treatment option, with only $25 \%$ of patients having access to the radiotherapy treatment in low and middle income countries compared to 50\% - 60\% in high income countries. The International Atomic Energy Agency (IAEA) established the Advisory Group on increasing access to Radiotherapy Technology in low and middle income countries (AGaRT) in 2009 under the Programme of Action for Cancer Therapy (PACT). AGaRT acts as a neutral facilitator to bring together radiotherapy users and major radiotherapy equipment suppliers, to encourage dialogue that will ensure that the unique radiotherapy service requirements of developing countries are met by the technology available [1]. According to data from IAEA-DIRAC database, 10/2010, 1 - 2 million people are served by one radiotherapy unit in Pakistan and India. By 2020, annual cancer cases in LMICs are expected to rise by 30\%, to 10.3 million.

Teletherapy by accelerator is clinically administered by the application of electro-magnetic radiation or electrons. Electromagnetic radiation may be X-rays; radiation produced, when an accelerated electron hits a target.

- Contact therapy $<100 \mathrm{kV}$.

- Superficial voltage $\sim 100 \mathrm{kV}$.

- Orthovoltage 150 - $300 \mathrm{kV}$.

- Megavoltage $\sim 4 \mathrm{MeV}-25 \mathrm{MeV}$.

The $\gamma$ rays are emitted from radioactive elements or isotopes. While ${ }^{226} \mathrm{Ra}$ and ${ }^{137} \mathrm{Cs}$ have been used as gamma emitters, the modern radiotherapy department frequently relies on ${ }^{60} \mathrm{Co}$ teletherapy machines which operate as megavoltage equipment.

Brachytherapy is the administration of radiation therapy by placing radioactive sealed source adjacent to or into tumours or body cavities. With this mode of therapy, a high radiation dose can be delivered locally to the tumour with rapid dose fall-off in the surrounding normal tissues. In the past, brachytherapy was carried out mostly with Radium or Radon sources in the world. Currently, use of artificially produced radionuclides such as ${ }^{137} \mathrm{Cs}$, ${ }^{192} \mathrm{Ir}$, and ${ }^{125} \mathrm{I}$, is rapidly increasing. ${ }^{192} \mathrm{Ir}$ sealed radioactive sources are generally employed for brachytherapy applications in Pakistan.

According to the removal of the radioactive sources, brachytherapy implants can be Temporary (sources are inserted and later removed) or Permanent (sources are inserted and left in place for the remainder of their active life).

According to the dose rate of the sources used, brachytherapy can be:

- Low Dose-Rate (LDR): 0.4 to 2.0 Gy per hour.

- Medium Dose-Rate (MDR): 2.0 to 12.0 Gy per hour.

- High Dose-Rate (HDR): >12.0 Gy per hour.

By International Commission on Radiation Units and Measurements (ICRU) definition, HDR is >12.0 Gy/h, although the usual dose rate employed in current HDR brachytherapy units is about 100 - 300 Gy per hour.

There are alternative methods of irradiating tumours, some virtually abandoned e.g. fast neutrons, and some under investigation e.g. protons, heavier ions, and boron neutron capture therapy. In boron neutron capture, tumours containing boron are irradiated with low energy (epithermal) neutrons to produce short-range alpha particles which are very efficient in killing cells. All these techniques are under development. In Pakistan teletherapy and brachytherapy is practiced. Unsealed sources of Iodine-131 and Phosphorus-32 have been routinely employed for the treatment of thyroid and blood disorders in Pakistan. Few radiolabeled compounds $\left({ }^{153} \mathrm{Sm-}\right.$ EDTMP and ${ }^{177}$ Lu-EDTMP) have also been used for bone pain palliation.

\section{Cancer Statistics}

In Pakistan we do not have a National Cancer Registry. Some institutions are now starting to develop their own Cancer Registry. According to the World Health Organisation annually 120,000 people in Pakistan are diagnosed with cancer. There were more than 1.4 million cancer patients in Pakistan. More than 80,000 people died each year due to this disease, including 40,000 from breast cancer.

The distribution of neoplasms of a total of 43,908 neoplasms, 21,549 were seen in males (49.08\%) and 22,359 
(50.92\%) in females registered at the Shaukat Khanum Memorial Cancer Hospital and Research Center (SKMCH \& RC, Lahore, Pakistan) in a fifteen year period extending from December 29, 1994 till December 31, 2009. Thirty eight thousand nine hundred and twenty seven (38,927 (88.66\%)) tumors were found in adults, whereas, 4981 (11.34\%) in children [2].

A retrospective analysis was carried out for the cancer patients of both genders of all age groups to determine frequencies of different cancers presented to KIRAN, Karachi, Pakistan from 1 January 2000 to 31 December 2008 [3]. A total of 16,351 cancer patients were registered at KIRAN during the nine-year period. Male cancers accounted for $48.1 \%$ and female cancers $51.8 \%$. Some 558 (3.4\%) were in children ( 0 - 15 years). The mean ages at presentation for males and females were $50 \pm 9.6$ and $47 \pm 7.4$ years respectively. In males the five most frequent malignancies were head and neck (32.6\%), lung (15\%), gastrointestinal tract (GIT) (6.9\%), lymphoma (6.1\%), and bone and soft tissue (4.9\%). In females breast cancer was the most common cancer accounting for $38.2 \%$ followed by head \& neck (15.1\%), cervical (5.5\%), ovarian (4.9\%) and GIT cancer (4.9\%) respectively. Overall cancer incidence in nine years in the KIRAN tertiary care cancer institution showed that head and neck cancers in males and breast cancers in females are most common, at rates almost highest in Asia. Mean age and male to female ratio in all other cancers are essentially comparable to other developing countries.

Pakistan Atomic Energy Commission (PAEC) was operating 14 Nuclear Medical Centers in 2011. The total patient turnover from 2005-2011 is given in Table 1 [4].

\section{Radiation Oncology Infrastructure}

Estimates of radiation oncology infrastructure in Pakistan for the years 2004 and 2009 in order to quantify trends in radiotherapy facilities, patient load and to identify the future needs were performed by N. Begum et al. [5]. The survey showed that Megavoltage teletherapy machines increased from 37 in 2004 to 41 in 2009. New patients registered in all radiotherapy centers were 33,369 in 2004 and 46,114 in 2009. Conventional simulators used for tumour localization increased from 15 to 21 and computerized tomography simulators from 0 to 7 . Radiation treatment planning systems for dose calculations of tumors and vital organs increased from 15 to 26 and brachytherapy units from 12 to 13. There were 725 patients per medical physicist in 2004 versus 632 in 2009. Patients per radiation oncologist were 439 in 2004 versus 549 in 2009. Number of radiotherapy technologists/shift/machine was 1.69 in 2004 versus 1.90 in 2009. Repair maintenance personnel improved from 2.11/2 megavoltage units in 2004 to 2.49 in 2009.

In another survey in 2009 showed that each radiotherapy centre covered a mean population of 1.96 million (range 3.54 - 19.63), with more access of cancer patients to the public sector due to low costs of radiotherapy treatment. There were only 56 radiation oncologists, 55 medical physicists, and 145 radiotherapy technologists. Further, only 20 Cobalt-60, 17 linear accelerators, 12 fluoroscopic simulators, and 4 CT simulators were available [6]. The majority of modern equipment and treatment delivery was available in the private sector. An estimated $55 \%-60 \%$ of all new cases of cancer were currently being referred for radiotherapy each year, and the existing services were inadequate.

In external beam radiation therapy (EBRT), the quality assurance (QA) of the radiation beam is crucial to the accurate delivery of the prescribed dose to the patient. One of the dosimetric parameters that require monitoring is the beam output, specified as the dose rate on the central axis under reference conditions. The International Atomic Energy Agency (IAEA)/World Health Organisation (WHO) postal audit dosimetry service provides an

Table 1. PAEC nuclear medical centers patient's turnover.

\begin{tabular}{cc}
\hline Year & Patients \\
\hline $2005-2006$ & 391,205 \\
$2006-2007$ & 411,678 \\
$2007-2008$ & 458,771 \\
$2008-2009$ & 485,732 \\
$2009-2010$ & 569,786 \\
$2010-2011$ & 648,625 \\
\hline
\end{tabular}


independent verification of dose rate calibration protocol by an international facility. Three photon beams were audited: a 6 MV beam from the low-energy linac and 6 and 18 MV beams from a dual high-energy linac. The agreement between Department of Radiation Oncology, Aga Khan University Karachi stated doses and the IAEA results was within 1\% for the two $6 \mathrm{MV}$ beams and within $2 \%$ for the $18 \mathrm{MV}$ beam [7].

Under the Regional Cooperative Agreement for Research, Development and Training related to Nuclear Science and Technology (RCA), 15 Member States of the International Atomic Energy Agency (IAEA) in the Asia and the Pacific region (Bangladesh, China, India, Indonesia, Japan, Republic of Korea, Malaysia, Mangolia, Mynmar, Pakistan, Philippines, Singapore, Sri Lanka, Thailand, Vietnam) have joined together to focus efforts on the issue of improving cancer treatment. The RCA project on "Improvement in Quality of Radiotherapy for Frequent Cancers in the Regions" (RAS/6/040) was successfully implemented between 2005 and 2008. The RCA Member States recognized the importance of the role and the contribution of radiotherapy to cancer treatment and care, and decided to produce a success story as a means to better inform for the wider public in the region. The overall objective was to improve the quality of the radiotherapy in recipient RCA Member States through enhancing national capacities in brachytherapy, improving the quality assurance in radiotherapy through the use of mission by the Quality Assurance Team on Radiation Oncology (QUATRO missions) and the adoption of QUATRO audit methodology [8].

Pakistan Nuclear Regulatory Authority (PNRA) in regulatory guide has described regulatory requirements for medical teletherapy facilities. It includes requirements for medical exposure, particularly general and design requirements for superficial, deep X-ray therapy, megavolt and electron beam therapy and sealed sources therapy facilities. The guide may be of interest for those who are concerned with the installations and design of new radiation facilities. Computation of protective barriers for shielding design of teletherapy facilities is also mentioned. This guide is intended mainly for use by medical physicists, radiotherapists and operators of teletherapy facilities who are directly responsible with radiation protection requirements [9].

Pakistan Institute of Engineering and Applied Sciences (PIEAS) Islamabad offers a two year Master course on "Radiation and Medical Oncology" in Pakistan [10]. Among the Courses that have been offered are:

Introduction to Nuclear Technology;

Principles of Radiotherapy and Cancer Chemotherapy;

Mathematical Modeling of Biological Systems and Epidemiology;

Radiation Detection, Protection and Instrumentation;

Tumor and Radiation Biology;

Diagnostics of Cancer;

Communication Skills;

Radiation \& Medical Oncology Laboratory;

Treatment Planning in radiation Oncology;

Pathophysiology of Tumors;

Management and Treatment of Individual Cancers;

Advanced Therapeutics in Oncology.

Thesis project and intensive clinical training in radiation and medical oncology are main part of the course.

\section{Role of IAEA}

Research activities supported by the International Atomic Energy Agency (IAEA), through Coordinated Research Program CRPs, are designed to encourage the acquisition and dissemination of new knowledge from the use of nuclear technologies and isotopic techniques. The CRPs bring together developing and developed countries to concentrate on the same research topic at the same time, and help the countries in sharing and using the knowledge and experience gained. A large number of CRPs were conducted by the IAEA and Regional Cooperation Agreement (RCA) to promote the radiotherapy activities for management of cancer in different parts of the world. Pakistan participation in CRPs on radiotherapy related topics are given in Table 2 [11].

\section{Radiotherapeutics Production}

At present almost 40 nuclear medical centers are functioning where more than one million patients are treated yearly. Radiopharmaceuticals are extensively used for therapeutic and diagnostic purposes in the nuclear medical centers. Isotope Production Division, PINSTECH, Islamabad is supplier of radiopharmaceutical to these centers. 
Table 2. Pakistan's participation in IAEA sponsored CRPs on radiotherapy.

\begin{tabular}{|c|c|c|c|}
\hline CRP code & Title/topic & Start & Close \\
\hline E33027 & $\begin{array}{l}\text { Improving outcomes in radiotherapy using new strategies of } \\
\text { treatment delivery with focus on oesophageal cancer }\end{array}$ & 2006-12-15 & 2013-01-28 \\
\hline E33008 & $\begin{array}{l}\text { Introduction of computerized dosimetry and database in radiotherapy of } \\
\text { carcinoma of the cervix in Asian countries (RCA) }\end{array}$ & 1990-06-01 & 1994-04-07 \\
\hline E33028 & $\begin{array}{l}\text { Investigation of optimal radiotherapy regimen and type of irradiation in } \\
\text { treatment of painful bone metastasis }\end{array}$ & 2007-07-01 & - \\
\hline E33011 & $\begin{array}{l}\text { Modern techniques in brachytherapy of cancer with special reference } \\
\text { to the developing countries }\end{array}$ & 1993-12-01 & $1998-12-31$ \\
\hline E33031 & Optimisation of radiotherapy in low resource settings: paediatric cancer patients & 2008-10-30 & - \\
\hline E33029 & Radiotherapy and chemotherapy in advanced non-small cell lung cancer & 2007-12-01 & - \\
\hline E33013 & $\begin{array}{l}\text { Randomised clinical trial of radiotherapy combined with Mitomycin C } \\
\text { in the treatment of advanced head and neck tumours }\end{array}$ & 1995-04-15 & $2003-03-26$ \\
\hline E33017 & Regional hyperthermia combined with radiotherapy for locally advanced cancers & $1997-12-15$ & 2002-12-15 \\
\hline E33035 & $\begin{array}{l}\text { Resource sparing curative radiotherapy for locally advanced squamous } \\
\text { cell cancer of the head and neck }\end{array}$ & 2010-11-15 & - \\
\hline E33025 & Resource sparing curative treatment in breast cancer & 2005-10-01 & 2013-01-30 \\
\hline E33023 & Resource sparing treatment of head and neck cancer & 2003-09-15 & 2009-01-16 \\
\hline E33033 & $\begin{array}{l}\text { Short course versus standard course radiotherapy, in elderly and/or fragile patients } \\
\text { with glioblastoma multiform (GBM) }\end{array}$ & 2009-02-04 & - \\
\hline E33016 & The use of radiotherapy in advanced cancer & $1995-12-15$ & $2000-12-20$ \\
\hline E35007 & Comparative assessment of teletherapy modalities & 2001-08-01 & 2003-05-28 \\
\hline E33009 & Computer-assisted radiotherapy planning for tumors of the head and neck (global) & $1990-12-15$ & 1994-04-07 \\
\hline E24014 & Development of procedures for in vivo dosimetry in radiotherapy & 2004-12-15 & $2008-10-13$ \\
\hline E24016 & $\begin{array}{l}\text { Development of quality audits for radiotherapy dosimetry for } \\
\text { complex treatment techniques }\end{array}$ & 2009-03-26 & 2013-01-28 \\
\hline E24015 & $\begin{array}{l}\text { Doctoral CRP on quality assurance of the physical aspects of advanced technology } \\
\text { in radiotherapy }\end{array}$ & 2008-06-15 & - \\
\hline E13033 & $\begin{array}{l}\text { Evaluation of the biological safety and clinical efficacy of }{ }^{177} \text { Lu-EDTMP for } \\
\text { bone pain palliation in metastatic prostate cancer (phase I/II clinical trial) }\end{array}$ & 2007-03-15 & 2012-04-04 \\
\hline E33006 & $\begin{array}{l}\text { Improvement of cancer therapy in Asian countries by the combination of treatment } \\
\text { by conventional radiation and physical or chemical means (RCA) }\end{array}$ & 1982-04-02 & $1987-11-30$ \\
\hline F22047 & Development of radiopharmaceuticals based on ${ }^{188} \mathrm{Re}$ and ${ }^{90} \mathrm{Y}$ for radionuclide therapy & 2008-04-01 & 2012-09-20 \\
\hline F22042 & $\begin{array}{l}\text { Development of therapeutic radiopharmaceuticals based on }{ }^{177} \mathrm{Lu} \\
\text { for radionuclide therapy }\end{array}$ & 2006-10-15 & $2010-06-22$ \\
\hline F22037 & Comparative laboratory evaluation of therapeutic radiopharmaceuticals & 2002-08-01 & $2005-12-12$ \\
\hline F22029 & Development of radioactively labelled cancer seeking biomolecules for targeted radiotherapy & $1997-12-15$ & $2001-12-14$ \\
\hline F22021 & $\begin{array}{l}\text { Optimization of the production and quality control of radiotherapeutic radionuclides } \\
\text { and radiopharmaceuticals }\end{array}$ & 1993-03-26 & $1999-12-30$ \\
\hline F22021 & $\begin{array}{l}\text { The standardization of I- } 131 \text { treatment for hyperthyroidism with an intent to optimize } \\
\text { radiation dose and treatment response (RCA) }\end{array}$ & 1995-01-15 & $2000-12-13$ \\
\hline E11007 & Quality control of advanced nuclear medicine equipment in Asia (RCA) & 1989-12-15 & 1993-7-8 \\
\hline E13026 & Comparative evaluation of radiopharmaceuticals for radiosynovectomy & 2002-10-15 & 2006-12-04 \\
\hline E12014 & $\begin{array}{l}\text { The standardization of I- } 131 \text { treatment for hyperthyroidism with an intent to optimize } \\
\text { radiation dose and treatment response (RCA) }\end{array}$ & 1995-01-15 & $2000-12-13$ \\
\hline
\end{tabular}


Nearly all nuclear medical centers perform diagnostic imaging, but $\sim 25$ centers perform radiotherapy.

Charged particle accelerators and nuclear reactors are employed for production of radioisotopes, however in bulk amounts these are produced in nuclear reactors [12] [13]. Production of radioisotopes started since Pakistan Research Reactor-1 (PARR-I) went critical in December 1965. The PARR-1 is a swimming pool type research reactor originally designed for a thermal power of $5 \mathrm{MW}$. Its core has been redesigned to operate with LEU fuel at a power level of 9 MW in 1992 and 10 MW in 1998.

Flux traps have been provided for incore irradiation of samples. In the first high power core the unperturbed neutron flux in the flux traps varies from $3.5 \times 10^{13}$ to about $2 \times 10^{14}$ with an average of about $1.3 \times 10^{14}$. In the equilibrium core, average thermal neutron flux of the order of $6 \times 10^{13}$ and $1.6 \times 10^{14} \mathrm{n} / \mathrm{cm} \cdot \mathrm{s}$ is expected at locations F-4 and C-7, respectively. In addition, the area outside the graphite reflector can be utilized for core side irradiation.

During irradiation of target a number of radionuclides of different half-lives and energies can be produced along with the radioisotope of interest. The irradiated target will often require chemical processing to separate the radioisotope of interest. Various facilities available for radioisotope processing are as follows:

1) Iodine-131 production cell (wet distillation technique). Maximum capacity per batch $10 \mathrm{Ci} / 370 \mathrm{GBq}$;

2) Iodine-131 production cell (dry distillation technique). Maximum capacity per batch $10 \mathrm{Ci} / 370 \mathrm{GBq}$;

3) Phosphorus-32 production cell (dry distillation technique). Maximum capacity per batch $10 \mathrm{Ci} / 370 \mathrm{GBq}$;

4) Sulpher-35 production glove box;

5) Molybdenum-99 loading facility for preparation of ${ }^{99 \mathrm{~m}}$ Tc generators;

6) Mo-99 (fission) production facility;

7) Hot cell with master slave manipulators;

8) Fume hoods and glove boxes (for small scale production of different radionuclides and R\&D work);

9) Workshop for target preparation and sealed source fabrication;

10) Laboratories for determination of radionuclidic, radiochemical and biological purity.

Various radionuclides produced at PINSTECH include, Phosphorus-32, Copper-64, Arsenic-77, Yttrium-90, Silver-111, Iodine-131, Samarium-153, Holmium-166, Lutetium-177, Gold-198/199 etc. Radiolabeled peptides, bone pain palliation agents $\left({ }^{153} \mathrm{Sm}\right.$-EDTMP, ${ }^{177} \mathrm{Lu}$-EDTMP), ${ }^{131} \mathrm{I}$-MIBG have also been developed and clinically evaluated in patients.

\section{Production of Iodine-131}

\subsection{Wet Distillation Technique}

The neutron irradiated tellurium is dissolved in an oxidizing medium (chromic and sulphuric acid) converting tellurium to telluric acid wherein the elemental iodine is released and converted to iodic acid $\left(\mathrm{HIO}_{3}\right)$. This is reduced with oxalic acid releasing elemental iodine vapor, (distilled at $140^{\circ} \mathrm{C}$ ) which is collected in alkaline scrubbers as sodium iodide in sodium sulphate/sodium bisulphate/ $\mathrm{NaOH}$ solution.

\subsection{Dry Distillation Technique}

The irradiated tellurium dioxide is heated at a temperature $\sim 700^{\circ} \mathrm{C}$ under vacuum. The ${ }^{131}$ I released from the matrix of the target as vapor is then trapped in carbonate/bicarbonate buffer.

Thyroid disorders are treated by ${ }^{131} \mathrm{I}$ [14]. Weekly demand of Iodine-131 in Pakistan is 4 - 5 Ci. Iodine-131 labeled MIBG (20 - $30 \mathrm{mCi}$ ) by isotope exchange method is also prepared for diagnostic applications. To minimize the radiation exposure of paramedical staff facility for preparation of Iodine-131 capsules for diagnosis and therapy are underway. Sixteen nuclear medical centers are using NaI $\left({ }^{131} \mathrm{I}\right)$ for the treatment of hyperthyroidism and well-differentiated thyroid cancer.

\section{Production of Phosphorus-32}

Neutron irradiated Sulfur is distilled at $450^{\circ} \mathrm{C}$ in a quartz furnace. Residual ${ }^{32} \mathrm{P}$ is dissolved in dilute $\mathrm{HCl}$ and $\mathrm{H}_{2} \mathrm{O}_{2}$ and finally purified by passing through cation exchange column. The product obtained is $\mathrm{H}_{3} \mathrm{PO}_{4}$. Yearly demand of ${ }^{32} \mathrm{P}$ is $<0.5 \mathrm{Ci}$. Small-scale production of ${ }^{32} \mathrm{P}$ is obtained by extraction in boiling water from neutron irradiated sulfur and purified by passing through cation exchange column. Sodium orthophosphate $\left({ }^{32} \mathrm{P}\right)$ is used by 10 medical centers for the treatment of blood disorders. 
Table 3. Beta particle emitting radionuclides produced at PINSTECH.

\begin{tabular}{cccccc}
\hline No & Radionuclide & Half-life & Target & Separation technique & Reference \\
\hline 1 & ${ }^{64} \mathrm{Cu} /{ }^{67} \mathrm{Cu}$ & $12.7 \mathrm{~h} / 61.9 \mathrm{~h}$ & $\mathrm{Zinc}$ & Ion exchange & {$[12]$} \\
2 & ${ }^{115 \mathrm{~m}} \mathrm{In}$ & $4.49 \mathrm{~h}$ & ${ }^{115} \mathrm{Cd}$ & Ion exchange & {$[13][14]$} \\
3 & ${ }^{113 \mathrm{~m}} \mathrm{In}$ & $99.48 \mathrm{~min}$ & ${ }^{113} \mathrm{Sn}$ & Ion exchange & {$[14]$} \\
4 & ${ }^{199} \mathrm{Au}$ & $\mathrm{Pt}$ & Adsorption & {$[15][17]$} \\
5 & ${ }^{111} \mathrm{Ag}$ & $7.139 \mathrm{~d}$ & $\mathrm{Pd}$ & Ion exchange/adsorption & {$[18]$} \\
6 & ${ }^{188} \mathrm{Re}$ & $16.98 \mathrm{~h}$ & Precipitation & {$[19]$} \\
7 & ${ }^{131} \mathrm{I}$ & ${ }^{188} \mathrm{~W}$ & Dry distillation & {$[20]$} \\
8 & ${ }^{90} \mathrm{Y}^{*}$ & $\mathrm{TeO}$ & Carrier added & {$[34]$} \\
9 & ${ }^{186} \mathrm{Re}^{*}$ & $64.1 \mathrm{~h}$ & $\mathrm{Y}$ & Carrier added & {$[34]$} \\
10 & ${ }^{153} \mathrm{Sm}^{*}$ & $90.64 \mathrm{~h}$ & $\mathrm{Re}$ & Carrier added & {$[21]$} \\
11 & ${ }^{166} \mathrm{Ho}^{*}$ & $46.75 \mathrm{~h}$ & $\mathrm{Sm}$ & Carrier added & Carrier added \\
\hline
\end{tabular}

${ }^{*}$ Carrier added.

\section{Other Beta Emitting Radionuclides Production}

Radionuclides that decay by $\beta^{-}$particle emission are used most extensively for radiotherapeutic applications in current clinical practices [15]. Utilization of $\beta^{-}$particle emitters provides a mechanism to produce a highly homogenous radiation dose even though their deposition is heterogeneously distributed in tumors. Radiochemical separation methods have been developed for obtaining no-carrier-added isotopes from neutron irradiated target matrix activity. Table 3 gives the details of target material, technique and the radionuclide produced in no-carrier-added or carrier added form [16]-[25].

Most work with ${ }^{188} \mathrm{~W} /{ }^{188} \mathrm{Re}$ generators has focused on an alumina-based column chromatography system. In which tungsten-188 $\left(\mathrm{T}_{1 / 2}=69 \mathrm{~d}\right)$ is adsorbed on alumina as hydrated tungsten oxide and ${ }^{188} \mathrm{Re}$ is eluted from column with normal saline. Unfortunately, however, ${ }^{188} \mathrm{~W}$ is produced by double neutron capture from ${ }^{186} \mathrm{~W}$, and thus is only available in low specific activity. High specific volume is necessary for several clinical applications of rhenium-188, including the use of ${ }^{188}$ Re liquid-filled balloons for coronary restenosis therapy, and for the preparation of ${ }^{188}$ Re-DEDC and HDD radiopharmaceuticals that are used for liver cancer therapy. Different concentration techniques using ion exchange and solvent extraction techniques have been developed at our institute [26]-[29].

Various radiolabeled compounds (peptides, colloid and bone seeking agent etc.) for radiotherapy have been synthesized and clinically evaluated. The radionuclide used during these studies includes ${ }^{90} \mathrm{Y},{ }^{131} \mathrm{I},{ }^{153} \mathrm{Sm},{ }^{166} \mathrm{Ho}$, ${ }^{177} \mathrm{Lu}$ and ${ }^{186,188} \mathrm{Re}$ [23] [24] [30]-[38]. Various IAEA CRPs on radiotherapeutic applications of labeled compounds have been carried out at different nuclear medical centers in Pakistan [11], however the radionuclides were produced at Pakistan Institute of Nuclear Science and Technology (PINSTECH) Islamabad (Table 3).

\section{Conclusion}

The facilities of diagnostic procedures are well established in Pakistan; however, radiotherapy units and use of radiotherapeutics are not up to mark. New facilities for radiotherapy are needed to fight increasing cases of cancer in the country. Use of radiotherapeutics, which can be produced locally, shall be enhanced for patient management.

\section{References}

[1] AGaRT (2013) The Advisory Group on Increasing Access to Radiotherapy Technology in Low and Middle Income Countries. http://cancer.iaea.org/agart.asp

[2] (2013) Collective Cancer Registry Report from Dec. 1994 up Till Dec. 2009. Cancer Statistics. 
http://www.slideshare.net/nadirqureshi996/cancer-registry-pakistan-1994-2009

[3] Hanif, M., Zaidi, P., Kamal, S. and Hameed, A. (2009) Institution-Based Cancer Incidence in a Local Population in Pakistan: Nine Year Data Analysis. Asian Pacific Journal of Cancer Prevention, 10, 227-230.

[4] Faheem, M. (2013) Role of PAEC in Health Sector. www.sassi.org/wpcontent/uploads/2012/07/2.-Dr-M-Faheem.pdf

[5] Begum, N., Nasreen, S. and Shah, A.S. (2012) Quantification of Trends in Radiation Oncology Infrastructure in Pakistan, 2004-2009. Asia-Pacific Journal of Clinical Oncology, 8, 88-94. http://dx.doi.org/10.1111/j.1743-7563.2011.01435.x

[6] Tunio, M.A. (2011) Present and Future of Radiotherapy in Developing Countries: Pakistan as an Example. 13th Annual Scientific Conference (ASCON), Science to Accelerate Universal Health Coverage, Dhaka, 14-17 March 2011. http://www.icddrb.org

[7] Jangda, A. and Hussein, S. (2012) Validating Dose Rate Calibration of Radiotherapy Photon Beams through IAEA/ WHO Postal Audit Dosimetry Service. Journal of Pakistan Medical Association, 62, 490-493.

[8] (2013) RCA Success Story in 2011, Improving the Quality of Radiotherapy in the Asia Pacific Region. RCA Regional Office. www.rcaro.org

[9] Ali, M. (2000) Regulatory Requirements for Medical Teletherapy Facilities. No. DNSRP-RED-4(111)/99, January 2000. Directorate of Nuclear Safety and Radiation Protection (Pakistan Nuclear Regulatory Board). www.pnra.org/medical\%20therapy.pdf

[10] (2013) Pakistan Institute of Engineering and Applied Sciences (PIEAS) MS Course on Radiation and Medical Oncology. http://www.jocation.com/course/MS_Radiation_Medical_Oncology_1544

[11] (2013) Coordinated Research Activities Website-IAEA. www.crp.iaea.org/

[12] Mushtaq, A. (2010) Reactors Are Indispensable for Radioisotope Production. Annals of Nuclear Medicine, 24, 759760. http://dx.doi.org/10.1007/s12149-010-0425-3

[13] Mushtaq, A. (2009) PET without Cyclotron. Annals of Nuclear Medicine, 23, 321-323. http://dx.doi.org/10.1007/s12149-009-0231-y

[14] Vini, L., Harmer, C. and McCready, V.R. (1996) Thyroid Cancer: A Review of Treatment and Follow-Up. Annals of Nuclear Medicine, 10, 1-7. http://dx.doi.org/10.1007/BF03165047

[15] Hoefnagel, C.A. (1998) Radionuclide Cancer Therapy. Annals of Nuclear Medicine, 12, 61-70. http://dx.doi.org/10.1007/BF03164831

[16] Mushtaq, A., Karim, H.M.A. and Khan, M.A. (1990) Production of No-Carrier-Added ${ }^{64} \mathrm{Cu}$ and ${ }^{67} \mathrm{Cu}$ in a Reactor. Journal of Radioanalytical and Nuclear Chemistry, 141, 261-269. http://dx.doi.org/10.1007/BF02035793

[17] Mushtaq, A. and Karim, H.M.A. (1993) Ion Exchange Behavior of Cadmium and Indium on Organic Anion and Cation Exchangers: A ${ }^{115} \mathrm{Cd} /{ }^{115 \mathrm{~m}} \mathrm{In}$ Generator. Radiochimica Acta, 60, 189-191.

[18] Mushtaq, A., Mansur, M.S. and Muhammad, A. (1996) Separation of Radioindium (NCA) from Neutron Irradiated Tin and Cadmium on Hydrated Pentoxide. Journal of Radioanalytical and Nuclear Chemistry, 212, 107-115. http://dx.doi.org/10.1007/BF02162342

[19] Akhter, M., Mushtaq, A., Karim, H.M.A. and Khan, M.A. (1994) Separation of ${ }^{199}$ Au (NCA) from Neutron Irradiated Platinum on Polythene. Radiochimica Acta, 64, 137-138.

[20] Mansur, M.S., Mushtaq, A. and Muhammad, A. (1995) Separation of ${ }^{111}$ Ag from Neutron Irradiated Natural Palladium. Radiochimica Acta, 68, 161-162.

[21] Khalid, M., Mushtaq, A. and Iqbal, M.Z. (2000) Separation of ${ }^{111}$ Ag from Neutron Irradiated Natural Palladium Using Alumina as an Adsorbent. Applied Radiation and Isotopes, 52, 19-22. http://dx.doi.org/10.1016/S0969-8043(99)00083-4

[22] Akhter, M., Mushtaq, A., Karim, H.M.A. and Iqbal, M.Z. (1996) Separation of NCA ${ }^{188}$ Re from Neutron Irradiated Natural Tungsten. Separation Science and Technology, 31, 1997-2000. http://dx.doi.org/10.1080/01496399608001026

[23] Jehangir, M., Mushtaq, A., Javed, M., Khalid, M. and Rusheed, A. (1998) Production of Iodine-131 via Dry Distillation Facility. NCD, P-117.

[24] Khalid, M. and Mushtaq, A. (2005) Preparation and in Vitro Stability of (n, $\gamma$ ) Yttrium-90 Hydroxyapatite. Applied Radiation and Isotopes, 62, 587-590. http://dx.doi.org/10.1016/j.apradiso.2004.08.046

[25] Sohaib, M., Mushtaq, A., Jehangir, M., Yousuf, M. and Perveen, A. (2007) Comparison of Animal Biodistribution of EDTMP Labeled with Various Beta Emitting Lanthanides. Journal of Nuclear Medicine, 48, 135.

[26] Mushtaq, A. (2003) Preparation of High Specific Volume Solutions of Technetium-99m and Rhenium-188. Applied Radiation and Isotopes, 58, 309-314. http://dx.doi.org/10.1016/S0969-8043(02)00353-6

[27] Mushtaq, A. (2004) Concentration of ${ }^{99 m} \mathrm{TcO}_{4}^{-} /{ }^{188} \mathrm{ReO}_{4}^{-}$by a Single Compact Anion Exchange Cartridge. Nuclear 
Medicine Communications, 25, 957-962. http://dx.doi.org/10.1097/00006231-200409000-00014

[28] Mansur, M.S., Mushtaq, A. and Jehangir, M. (2006) Concentration of ${ }^{99 \mathrm{~m}}$ Tc-Pertechnetate and ${ }^{188}$ Re-Perrhenate. Radiochimica Acta, 94, 107-111. http://dx.doi.org/10.1524/ract.2006.94.2.107

[29] Mushtaq, A., Bukhari, T.H. and Khan, I.U. (2007) Extraction of Medically Intresting ${ }^{188}$ Re-Perrhenate in Methyl Ethyl Ketone for Concentration Purposes. Radiochimica Acta, 95, 535-537.

[30] Pervez, S., Mushtaq, A. and Jehangir, M. (1998) Simple Purification and Radiochemical Testing of ${ }^{131}$ I-Metaiodobenzylguanidine. Nuclear Science Journal, 35, 364-368.

[31] Mushtaq, A., Pervez, S. and Haider, I. (2000) Preparation of ${ }^{188}$ Re-Lanreotide Peptide and Its Quality Control. Radiochimica Acta, 88, 495-498. http://dx.doi.org/10.1524/ract.2000.88.8.495

[32] Pervez, S., Mushtaq, A. and Arif, M. (2002) Preparation of ${ }^{188}$ Re-Labeled Hydroxyapatite for Radiosynovectomy. Journal of Radioanalytical and Nuclear Chemistry, 254, 383-385. http://dx.doi.org/10.1023/A:1021604806814

[33] Pervez, S., Mushtaq, A. and Jehangir, M. (2002) Synthesis and in Vitro Evaluation of ${ }^{188}$ Re-Biotinyl-Hydrazino-EDTA. Turkish Journal of Nuclear Sciences, 28, 1-9.

[34] Pervez, S., Mushtaq, A., Arif, M. and Chohan, Z.H. (2003) ${ }^{188}$ Re-Glucoheptonate: A Radiopharmaceutical for Intravascular Radiation Therapy. Journal of Radioanalytical and Nuclear Chemistry, 256, 293-296. http://dx.doi.org/10.1023/A:1023945603430

[35] Pervez, S., Mushtaq, A. and Arif, M. (2003) Formulation of a Freeze-Dried Kit for ${ }^{188}$ Re-MAG 3 and Its Quality Control. Journal of Radioanalytical and Nuclear Chemistry, 257, 421-424. http://dx.doi.org/10.1023/A:1024764703623

[36] Pervez, S., Mushtaq, A., Arif, M. and Chohan, Z.H. (2003) ${ }^{188}$ Rhenium-EDTMP: A Potential Therapeutic Bone Agent. Journal of Radioanalytical and Nuclear Chemistry, 257, 417-420. http://dx.doi.org/10.1023/A:1024712719553

[37] Pervez, S. and Mushtaq, A. (2005) Preparation, Quality Control and Stability of Iodine-131-Lanreotide. Journal of Radioanalytical and Nuclear Chemistry, 266, 265-268. http://dx.doi.org/10.1007/s10967-005-0902-7

[38] Ishfaq, M.M., Mushtaq, A. and Jawaid, M. (1999) Experience on the Neutron Activation of Natural/Enriched Re, Sm, and Ho Nuclides in a Reactor for the Production of Radiotherapeutic Radionuclides. Biological Trace Element Research, 71-72, 519-526. 